\title{
Genome Editing by Natural Genetic Transformation in Streptococcus mutans
}

\author{
D. A. Morrison ${ }^{23}$, R. Khan ${ }^{1}$, R. Junges ${ }^{1}$, H. A. Åmdal ${ }^{1}$, F. C. Petersen ${ }^{1}$
}

${ }^{1}$ Department of Oral Biology, Faculty of Dentistry, University of Oslo, Norway; ${ }^{2}$ Department of Biological Sciences, College of Liberal Arts and Sciences, University of Illinois at Chicago, USA

${ }^{3}$ Corresponding Author: D. A. Morrison, Room 4102 MBRB, 900 South Ashland Ave, Chicago, IL USA 60607

E-mail addresses:

Donald MorrisonＤAMorris@uic.edu

Rabia Khan_rabia.khan@odont.uio.no

Roger Junges $\quad$ roger.junges@ odont.uio.no

Heidi Åmdal h.a.amdal@ odont.uio.no

Fernanda Petersen f.c.petersen@odont.uio.no

1 Keywords: pheromone, competence, natural transformation, markerless mutagenesis
Abbreviations
CDM, chemically defined medium
CSP, competence-stimulating peptide
XIP, SigmaX-inducing peptide
PCR, polymerase chain reaction 


\section{Introduction}

Genome editing has gained currency as a shorthand to represent a family of recently developed strategies for directed mutation, in which DNA disruption by clustered regularly interspaced short palindromic repeats (CRISPR) nucleases at specific sites within eukaryotic genomes is coupled with recombinational repair of the damage to introduce arbitrarily designed genetic changes at chosen sites. Equivalent repair-initiating damages are also introduced at unique sites in eukaryotic genomes by use of zinc finger nucleases (ZFNs) or the class of transcription-activator-like effector nucleases (TALENs). DNA selected or designed and produced in vitro is then introduced as a substrate for the repair process. The resulting specificity of target for the introduced sequences creates dramatic advantages over traditional transgenic approaches, which introduce trans DNA at random or poorly controlled sites, as emphasized by the new moniker. Strictly speaking, genome editing has long been practiced routinely as a tool of bacterial genetics, by use of natural bacterial genetic transformation as the facilitating and targeting mechanism, and by manipulation of donor DNA in vitro to provide arbitrary sequence alterations. In this case, targeting damage is not required, as competence development creates a specialized cell equipped with two dozen proteins that together accomplish targeted gene replacement by extracting long multi-gene segments of ssDNA from native DNA molecules, preserving them after transport, and efficiently inserting them with high precision at matching resident sequences (Johnston et al., 2014). No special targeting devices are needed, because the donor DNA itself is used by the native inducible recombination system for precise targeting anywhere in the genome. Because yields of recombinants among recipient cells are often in the .01-1\% range or lower, most such designs have retrieved rare recombinants by incorporation of a readily selectable marker linked to the desired mutation.

A drawback to the use of selective markers for gene inactivation is the introduction of new genes unrelated to the mutant phenotype of interest, risking phenotypic effects of the inserted genes and accumulation of multiple irrelevant new genes during successive steps of mutagenesis. To avoid such drawbacks, various strategies have been developed for achieving gene deletion or modification without introduction of permanent selective markers unrelated to the desired mutation in both the archaea and the bacteria. Some use the Cre-loxP system for excision of the unwanted marker (Banerjee and Biswas, 2008; Fontaine et al., 2010b; Leibig et al., 2008). Others use a recombinant plasmid for insertion by single homologous cross-over followed by a different 
crossover to remove unwanted plasmid elements (Biswas et al., 1993; Keller et al., 2009; Lipscomb et al., 2011; Olson and Lynd, 2012). A third approach is illustrated by an elegant cloning-independent counter selection approach using transformation with a pheS-ermAM cassette to create markerless mutations by counter selection with $\mathrm{p}-\mathrm{Cl}-\mathrm{Phe}$. The two-step procedure inserts a highly expressed mutant pheS allele that confers p-Cl-Phe sensitivity at a target site using selection for erythromycin resistance, then uses a second transformation with a mutant construct carrying the desired new allele to replace the temporary pheS-ermAM cassette by double-crossover recombination and selecting for loss of pheS (Xie et al., 2011). Using the high specificity of natural genetic transformation, many versions of these two steps have been developed, especially by relying on a variety of strong counter selections at the second step, based on initial incorporation of two linked genes - one to provide selection for insertion, and a second to allow selection for the excision event (Debowski et al., 2012; Farkas et al., 2012; Thiel et al., 2014; Zhang and Whitaker, 2012). However, the design of suitable selectable and counter-selectable markers can be complex. In a fourth, more general strategy, co-transformation by a mutagenic PCR amplicon donor and a counter selectable plasmid selects for the minority of competent cells, which are subsequently screened by colony PCR for incorporation of the desired mutation; removal of the $\mathrm{T}^{S}$ plasmid then allows recovery of an unmarked mutant (Biswas et al., 2007).

The general principle underlying these methods has been to combine recombination events of low probability but high precision with strong selection to achieve predictable genetic rearrangements at a practical frequency. As each such selection strategy has potential disadvantages, we sought to learn whether the efficient and precise targeted recombination reaction of natural genetic transformation itself could be utilized for direct one-step mutagenesis while bypassing selection steps entirely. All systems of natural genetic transformation described in bacteria and archaea to date transfer genetic information from extracellular DNA molecules into the recipient genome in two steps, following a pattern characterized in detail for Streptococcus pneumoniae and Bacillus subtilis. First, a transport apparatus extracts ssDNA segments of arbitrary length from DNA encountered by the cell, starting at a single-strand break introduced at random (Lacks et al., 1967; Morrison and Guild, 1973). Although ssDNA is subject to attack by intracellular nucleases, competent cells are in fact strongly protective of the imported ssDNA. Although short fragments are frequently degraded, long fragments are quite thoroughly protected (Morrison and Guild, 1972). The second step, homologous recombination, then produces long 
stretches of heteroduplex containing integrated donor nucleic acid (Gurney and Fox, 1968). In some species, $100 \%$ of cells in a laboratory culture become highly competent at the same time; in others, although only a minority becomes competent, these few can individually be highly competent. The efficiency of gene replacement depends on the length of donor DNA strands, reaching $50 \%$ or more for pure donor with lengths above $4 \mathrm{~kb}$ and diminishing to zero below 300 bp (Cato and Guild, 1968). Thus, when combined with use of PCR to prepare unique donor fragments of chosen design, the high efficiency of recombination in natural transformation should in principle make direct genome editing practical. The power of large donor DNA fragments for gene replacement by natural transformation was illustrated recently in two contrasting circumstances: in $S$. pneumoniae, where all cells are simultaneously highly competent, and in Vibrio cholerae, where few cells are competent (Dalia et al., 2014). Observation of a high proportion of double transformations in V. cholerae demonstrated that once formed, DNA uptake and incorporation can be highly efficient in competent cells of this species .

The human oral commensal S. mutans, first described in 1924 (Clarke, 1924), is associated with caries and appears to have evolved in specific adaptation to human sugar-rich diets (Cornejo et al., 2013; Loesche, 1986). Discovery of natural genetic transformation in S. mutans in 1981 (Perry and Kuramitsu, 1981) has provided the basis for many tools for its genetic manipulation, facilitating study of its metabolism and cariogenic potential. While low and variable levels of transformation in routine laboratory culture made selective markers especially important in developing these tools, recent advances in characterization of the control of competence development in this species have improved available levels of competence significantly. First, the peptide pheromone XIP (sigX-inducing peptide) can be used to intervene at the heart of competence regulation, by directly provoking a high rate of synthesis of SigX, the central competence regulator (Mashburn-Warren et al., 2010). Second, competence in this species is reported to be bimodal in rich media, but unimodal in peptide-free chemically defined media (Lemme et al., 2011; Reck et al., 2015; Son et al., 2015; Son et al., 2012). This immediately suggests a chemically defined culture medium as especially suitable for development of strategies for direct genome editing, which would depend on efficient gene incorporation by most or all cells exposed to DNA. Although improved levels of transformation in chemically defined media have been reported (Shah and Caufield, 1993), a direct measurement of maximal replacement rates is not available. Here we report that in $S$. mutans the competent state can be more like that of $S$. 
pneumoniae than that of $V$. cholerae, coupling a high fraction of competent cells and a high rate of gene replacement, and show that XIP-induced competence in S. mutans can provide a practical route to convenient direct genome editing, without resort to linked selective markers.

\section{Methods}

\subsection{Bacterial strains and culture media}

The S. mutans strains used in the study are listed in Table 1. SM068, a sigX reporter derivative of strain UA159, was used as the recipient for most transformation assays. All strains were cultured in tryptic soy broth (TSB) or a chemically defined medium (CDM) (Vanderijn and Kessler, 1980). CDM was assembled weekly from the stable stock solutions described previously (Chang et al., 2011). Media were solidified when needed with 1.5\% Bacto agar (Becton, Dickinson and Company). Antibiotics were used at the following concentrations: kanamycin (Kan), $500 \mu \mathrm{g} / \mathrm{mL}$; erythromycin (Erm), $10 \mu \mathrm{g} / \mathrm{mL}$; spectinomycin (Spc), $500 \mu \mathrm{g} / \mathrm{mL}$. The mature competence pheromone CSP18 (Petersen et al., 2006) (NH2-SGSLSTFFRLFNRSFTQA-COOH) was obtained ) as a custom synthetic peptide (GenScript Corporation, NJ), at 98\% purity and stored as sterile $1 \mathrm{mM}$ solution in water at $-20^{\circ} \mathrm{C}$. The alternative competence pheromone XIP (NH2-GLDWWSL-COOH; 98\% purity; GenScript) was reconstituted with $20 \mu$ dimethyl sulfoxide (DMSO) (Sigma-Aldrich), to which $1 \mathrm{~mL}$ distilled water was added to give a final concentration of $10 \mathrm{mM}$.

\subsection{Luciferase reporter assays}

For detection of luciferase activity, precultures of the PsigX-luciferase strain SM068 grown in $\mathrm{CDM}$ to an optical density at $600 \mathrm{~nm}\left(\mathrm{OD}_{600}\right)$ of 0.5 were prepared as described below for the transformation assays. For inoculation, pre-cultures were diluted 10-fold in CDM or TSB in the presence or absence of $1 \mu \mathrm{M}$ XIP or $0,25 \mu \mathrm{M}$ CSP, respectively. Aliquots of $100 \mu$ were then distributed among the wells of black 96-well microtiter plates with transparent bottoms (Nunc Thermo Scientific). Wells with CDM or TSB medium without the inoculum were included as blanks. A volume of $10 \mu \mathrm{l}$ of a $1 \mathrm{mM}$ d-luciferin solution (Synchem, Felsberg-Altenberg, Germany) was then added to each well, and the cultures were incubated at $37^{\circ} \mathrm{C}$ in air. Relative 
luminescence units (RLU) and $\mathrm{OD}_{600}$ were measured at various time intervals during growth by reading the plates in a multi-detection microplate reader (Synergy HT; BioTek, Winooski, VT).

\subsection{Marked mutant strain construction}

Three new marked deletion strains (SM033, SM045, and SM156) were constructed by PCR-ligation mutagenesis (Lau et al., 2002), using 1-kb fragments amplified from a genomic template up- and down-stream of a target gene, and a third fragment containing a selective antibiotic marker, amplified from a plasmid. After digestion with restriction enzymes and ligation by T4 DNA ligase (New England Biolabs), the three-component ligation product was amplified and transformed into S. mutans UA159 by culturing cells with CSP18 as described previously (Petersen et al., 2006). The structure of the mutant targeted locus in a selected transformant was verified by amplification of the predicted junction products. Details of individual constructions and a list of primers designed for each purpose are given in Supplemental Table 1.

\subsection{Markerless mutant strain construction}

To construct the markerless mutant SM177, with inversion of a putative SigX-box promoter upstream of the bacteriocin regulatory gene comE, fragments of $4.3 \mathrm{~kb}$ and $3 \mathrm{~kb}$ were amplified from strain UA159 with the primer pairs FP916-FP936 and FP935-FP913, respectively. Primers FP935 and FP936 were complementary to each other, with a central region comprising the inverted SigX-box sequence. The overlapping sequences were used for fusion of the two PCR products, in a ligase-free PCR reaction that used less than $5 \mathrm{ng}$ of each of the two amplified sequences and the nested primers FP009 and FP910, to produce a conjoint amplicon of $5757 \mathrm{bp}$. After transformation of competent cells of strain SM068, as described in section 2.4, colonies from TSB plates were screened by PCR (section 2.5), colony-purified, and re-screened to identify a clone containing the inversion but no WT SigX-box. Similar designs and procedures yielded strains SM179, SM189 and SM190, as detailed in Supplemental Table 1.

\subsection{Transformation assays}

The standard transformation was done as previously described, with slight modifications (Desai et al., 2012). Pre-cultures were prepared by transferring fresh colonies grown on TSB agar 
plates to liquid $\mathrm{CDM}$, followed by growth at $37^{\circ} \mathrm{C}$ to an $\mathrm{OD}_{600}$ of 0.5 . The pre-cultures were then stored at $-80^{\circ} \mathrm{C}$ with $15 \%$ glycerol until use. On the day of transformation, the pre-cultures were diluted 1:10 in $\mathrm{CDM}$ and incubated at $37^{\circ} \mathrm{C}$ until reaching the exponential phase at $\mathrm{OD}_{600} 0.1$. Unless specified otherwise, the cultures were then exposed to $0.1-1 \mu \mathrm{g} / \mathrm{mL}$ DNA and $1 \mu \mathrm{M}$ XIP for $2-3 \mathrm{~h}$ at $37^{\circ} \mathrm{C}$ in closed tubes. Portions of the culture were then spread on TSB plates with relevant antibiotic, if any. After $15-36$ hours at $37^{\circ} \mathrm{C}$ in $5 \% \mathrm{CO}_{2}$, colonies were counted. For routine quantitation of transformants, $3-\mu \mathrm{L}$ or $20-\mu \mathrm{L}$ drops from serial dilutions were spotted on the surface of selective or non-selective TSB/agar plates, allowed to dry, and inspected for small colonies after $20-36 \mathrm{~h}$ incubation at $37^{\circ} \mathrm{C}$ in $5 \% \mathrm{CO}_{2}$. Spots with $3-100$ colonies were counted under a dissecting microscope.

\subsection{Colony genotyping assays}

Colonies on non-selective plates were screened by PCR using primers specific, respectively, for the donor and recipient alleles at targeted loci. Briefly, a 10- $\mu \mathrm{L}$ PCR reaction was set up with $0.06 \mu \mathrm{L}$ of each primer, $0.2 \mu \mathrm{L}$ dNTP mix $(10 \mathrm{mM}), 1 \mu \mathrm{L} 10 \mathrm{x}$ buffer, $1 \mu \mathrm{L} \mathrm{MgCl}_{2}$ (25mM), $0.2 \mu \mathrm{L}$ TrueStart Taq polymerase (Thermo Scientific; $5 \mathrm{U} / \mu \mathrm{L}$ ) and $7.5 \mu \mathrm{L}$ of nucleasefree distilled water. Each colony was picked with a sterile pipette tip for transfer to the PCR-mix and a TSB stock plate. PCR cycles were: $3 \mathrm{~min}$ at $95^{\circ} \mathrm{C} ; 25$ repetitions of $30 \mathrm{~s}$ at $95^{\circ} \mathrm{C}, 30 \mathrm{~s}$ at $55^{\circ} \mathrm{C}$, and $50 \mathrm{~s}$ at $72^{\circ} \mathrm{C}$; and a final extension for $5 \mathrm{~min}$ at $72^{\circ} \mathrm{C}$.

\subsection{Preparation of genomic donor DNA}

Genomic donor DNA was extracted from strains according to Lin Tao (personal communication), as described previously (Desai et al., 2012).

\subsection{Preparation of donor DNA amplicons}

Primers used for amplification of donor DNA from existing mutants are listed in Supplemental Table 1 and corresponding amplicons are described in Table 2. The PCR reactions contained: $10 \mu \mathrm{L} 5 \times$ Q5 buffer, $1 \mu \mathrm{L} 10 \mathrm{mM}$ dNTP mix, $0.25 \mu \mathrm{L}$ of $100 \mu \mathrm{M}$ primers, $50 \mathrm{ng}$ template, and 1 unit of Q5 DNA polymerase (New England BioLabs) in $50 \mu \mathrm{L}$ total volume. Initial denaturation at $98{ }^{\circ} \mathrm{C}$ for $30 \mathrm{~s}$ was followed by 5 cycles of $98{ }^{\circ} \mathrm{C}$ for $10 \mathrm{~s}, 54{ }^{\circ} \mathrm{C}$ annealing for 30 
s, and $72{ }^{\circ} \mathrm{C}$ extension for $90 \mathrm{~s}, 25$ cycles of $98{ }^{\circ} \mathrm{C}$ for $30 \mathrm{~s}, 65^{\circ} \mathrm{C}$ annealing for $30 \mathrm{~s}$, and $72{ }^{\circ} \mathrm{C}$ extension for $2 \mathrm{~min}$, and a final $72{ }^{\circ} \mathrm{C}$ extension for $5 \mathrm{~min}$. Amplicons used for fusion PCR were purified using the GeneJET PCR Purification Kit (Thermo Scientific). The fusion overlap PCR reactions generating mutagenic donor amplicons consisted of $100 \mathrm{ng}$ of each of the two amplicons to be fused, $10 \mu \mathrm{L} 5 \times \mathrm{Q} 5$ reaction buffer, $0.3 \mu \mathrm{L}$ of $100 \mu \mathrm{M}$ "nested" primers, $1 \mu \mathrm{L} 10 \mathrm{mM}$ dNTP mix, and 0.5 units of Q5 DNA polymerase in $50 \mu \mathrm{L}$ total volume. The PCR program was set to: 98 ${ }^{\circ} \mathrm{C}$ initial denaturation for $30 \mathrm{~s} ; 30$ cycles of denaturation at $98{ }^{\circ} \mathrm{C}$ for $10 \mathrm{~s}, 62^{\circ} \mathrm{C}$ annealing for 30 $\mathrm{s}$, and $72{ }^{\circ} \mathrm{C}$ extension for $30 \mathrm{~s} / \mathrm{kb}$ of product; and a final extension at $72{ }^{\circ} \mathrm{C}$ for $5 \mathrm{~min}$. The amplified products were used directly for transformation.

\section{Results and Discussion}

\subsection{Optimal conditions for high efficiency of gene replacement in S. mutans}

We explored the use of the SigmaX-inducing peptide, XIP, to induce competence in the chemically defined medium, CDM, because this medium supports unimodal competence in $S$. mutans in response to XIP (Lemme et al., 2011; Reck et al., 2015; Son et al., 2015; Son et al., 2012). A second reason was that the XIP receptor, ComR, is the proximal regulator of $\operatorname{sig} X$, suggesting that intervention at this stage of the competence signaling pathway would likely be the least complex strategy for obtaining optimal competence development (Mashburn-Warren et al., 2010). Because the bacteriocin-regulating pheromone known as CSP is often used to stimulate development of competence in S. mutans in rich media (Li et al., 2001), a direct comparison of the transcriptional responses to CSP vs. XIP was carried out to learn which condition for competence development might be superior when the goal is a maximal rate of gene replacement or alteration. To compare induction of competence using XIP in CDM vs. CSP in a richer medium, a single culture was split and incubated in parallel in the two media with respective pheromone peptides (Fig. 1). Monitoring of luminescence from a psigX reporter showed that although growth rates were higher in TSB than in CDM, sigX expression reached higher levels and persisted for a longer time in CDM, explaining the long period of active DNA uptake described below (section 3.2). 
To ask whether any density dependence remained when synthetic XIP was used to bypass the ComRS quorum-sensing step in competence regulation, CDM cultures were treated with XIP at various low cell densities. The quality of competence, assessed as transformants per $\mathrm{mL}$ achieved during a 2-h exposure to XIP and DNA, was independent of culture density over a wide range of initial culture densities (0.001 to 0.02) and densities at the start of DNA exposure (0.009 to 0.11 ) (Fig. 2). In contrast to early reports for $S$. mutans that a specific culture density is optimal for competence development (Lindler and Macrina, 1986), this result indicates that the provision of synthetic XIP short-circuits much density dependence, as is the case for supplying pheromone peptides to other naturally transformable streptococci (Fontaine et al., 2010a; Havarstein et al., 1995).

\subsection{Competence of $\mathrm{S}$. mutans in CDM is long-lasting}

To optimize the protocol for transformation further, we explored the kinetics of competence development in CDM cultures treated with XIP. Competence, measured directly as the momentary rate of DNA uptake, followed a characteristic long time course (Fig. 3A). During the first 20 min after XIP introduction, almost no cells exhibited competence. There followed a period of 80 min during which capacity for DNA uptake constantly increased. Beyond 80 min, cells remained highly competent for at least two additional hours. Environmental pH is a critical factor in $S$. mutans competence, which is optimal at values close to $\mathrm{pH} 7$, and reduced under acidic conditions (Guo et al., 2014; Son et al., 2015). Monitoring of $\mathrm{pH}$ revealed that the initial $\mathrm{pH} 7 \mathrm{of}$ our cultures remained unchanged for at least $7 \mathrm{~h}$, which may explain in part the long period of sustained competence. This prolonged state of competence indicated that the best yield of transformants might be obtained by extended exposure to donor DNA. Indeed, introduction of donor DNA at either $50 \mathrm{~min}$ or $150 \mathrm{~min}$ after XIP led, in either case, to continuous DNA uptake at a constant rate during at least 200 min (Fig. 3B).

\subsection{High efficiency of incorporation of large unique donor DNA amplicons}

A critical parameter in determining the yield of recombinants during transformation is expected to be the complexity of donor DNA. For example, a 7-kb PCR product carrying a gene of interest is $~ 300$-fold less complex than genomic DNA from the same donor strain, and thus contains much less irrelevant competitor DNA material than a genomic DNA preparation. The 
value of using such enriched donors is illustrated for S. mutans in experiments collected in Fig. 4, where cultures in CDM were treated with XIP and a 6.3-kb PCR product carrying a kanamycinresistance insert (aRJ102) at final concentrations ranging from 0.3 to $150 \mathrm{ng}$ per $\mathrm{mL}$. Direct comparison of CFU on Kan medium vs unselective medium showed that maximal transformant yields of approximately $40 \%$ were achieved with amplicon concentrations of $75 \mathrm{ng} \mathrm{mL} \mathrm{m}^{-1}$ or above (Fig. 4).

In this example, the entire $\operatorname{dexA}$ gene was replaced by non-homologous DNA, in the form of the $\mathrm{Kan}^{\mathrm{R}}$ marker. Although these events were monitored by use of the selective marker, the efficiency of replacement was so high as to make the selection step appear unnecessary, so long as some tool is available to screen a few dozen colonies for incorporation of the new material. Since any mutation can in principle be detected by appropriately designed PCR reactions, it seemed likely that arbitrary base changes could be readily introduced in this way using a markerless large donor DNA construct.

\subsection{Introduction of an eight-base inversion}

As a first test of such direct, 'markerless,' genome editing and to investigate a promoter region putatively recognized by a known regulator, we designed a mutation in which an 8-bp motif suspected of being a SigX-dependent promoter for the gene comE (Reck et al., 2015) was substituted by its reverse complement sequence. Assembly of a 5757-bp donor amplicon by overlap extension PCR and design of primer pairs to screen clones after transformation are described in Section 2.4. After extended incubation of this donor amplicon with a competent culture in CDM, two dozen colonies on TSB were screened by PCR for presence of the donor allele; screening two dozen subclones from positive cultures was sufficient to recover pure transformant clones (data not shown). Optimization of incubation time in the presence of XIP and donor DNA, resulted in up to $66 \%$ colonies with only the mutant allele (Fig. 5).

\subsection{Efficiency depends on size of donor fragments}

While the yield of recombinants from amplicon donors can be very high, it is expected to depend on donor size. In the related competence system of $S$. pneumoniae, for example, recombinant yield for sheared genomic DNA donors is roughly proportional to length of DNA 
290 donor molecules within the range of $1-10 \mathrm{~kb}$ (Cato and Guild, 1968) and the yield of 291 recombinants from donor amplicons varies over a 10,000-fold range when homologous arms vary 292 between 100 and 2000 bp (Lau et al., 2002). To explore the upper range of this relationship for $S$. 293 mutans, donor amplicons of different sizes, but directing the same allelic change, were constructed 294 by amplification from genomic templates by use of symmetrically placed primers designed at different distances either from the small inversion mutation described above or from a Kan insert in gene SMU.60. Figure 6, comparing gene replacement rates for the amplicon donors with flanking homology ranging from $0.5-3 \mathrm{~kb}$, indicates that a similarly strong size dependence does hold for $S$. mutans, with efficiency increasing little if at all for extension of flanking homology arms above the size of $2 \mathrm{~kb}$, but decreasing severely below that size. Very similar size dependence was seen for both types of allele: the small sequence change and the larger gene insertion. Figures 6 and 7 both indicate that a maximal rate of gene replacement is reached with 2 to $3 \mathrm{~kb}$ flanking regions of homology; it is not known why $\operatorname{dexA}:$ kan and 8-bp inversion donors gave higher transformation efficiency than the SMU.60::kan donor, but the difference was reproducible in different experiments.

Results of additional transformation trials indicated that targeted mutagenesis by this strategy could be achieved routinely. Using three recipient derivatives of UA159, two donor DNA amplicons (8 and $6 \mathrm{~kb}$ ), in 24 trials on five different days with DNA at $0.15-1 \mu \mathrm{g} / \mathrm{ml}$, cultures at OD 0.04 to 0.1 , and exposure times of $2.5-6 \mathrm{~h}$, transformation frequencies were observed ranging from $17 \%$ to $60 \%$ (Supplemental Table 2).

\subsection{Extended incubation increases recombinant yield and allows segregation of pure} transformant clones

The chaining growth habit of streptococci is likely to ensure that colonies recovered unselectively soon after transformation are mixed - containing both recombinants and parental cells. However, as gene replacements were very frequent, it appeared possible that pure transformant colonies might be generated at a significant rate during moderately extended incubation in CDM. In two trials, we tested for such clones using various lengths of incubation with DNA and XIP exposure, by testing individual colonies by PCR for presence of donor and recipient alleles (Fig. 5, Fig. 7). Pure clones were found at a significant frequency after incubations as short as $3 \mathrm{~h}$. 
322 3.7. Additional examples of genome sequence editing without use of selective resistance markers.

323 Illustrating the utility of direct genome editing, two additional markerless mutations were 324 designed and created using this method (for design details, see Supplemental Table 1). First, a 325 single-base replacement was made in the putative ORF c105 (Human Oral Microbiome Database 326 annotation; www.homd.org) to create a stop codon, without making any change to the translation 327 product of an overlapping ORF, SMU.60. A T61178G substitution retained Val75 in SMU.60 328 (GTT > GTG) but replaced Leu16 in the overlapping ORF c105 by a stop codon (TTA > TGA) in 329 strain SM068, to create strain SM188. Primer pairs to verify the mutation were designed so that 330 the 3' terminal base of one of them corresponded to the mutated base. Touch-down PCR starting 331 with high annealing temperatures that were decreased for each PCR cycle ensured specific 332 amplification. Second, a deletion of a putative direct-repeat binding site for ComE was made by 333 removal of 39 bp upstream of the comE gene in strains SM091 and SM134, creating strains 334 SM189 and SM190. In this case, the mutated region was distinguished from the wild-type by the 335 reduced size of the product amplified by PCR in the mutant. Figure 8 summarizes the range of 336 structural changes that we have obtained using direct genome editing. 


\subsection{Applications to other strains of S. mutans and to other streptococcus species}

The results of these initial experiments on the use of pure-gene donors suggest that direct genome editing in S. mutans strain UA159 will be powerful and practical. Already, 10-50\% of CFU were regularly been found to carry a donor cassette gene that had been provided in 5-7-kb pure gene fragments, as prepared by PCR amplification. Similarly high replacement rates were obtained for the markerless mutation design that included an 8-bp inversion of a SigX-box in the promoter regions. Other designs included a 39-bp deletion and a 1-bp substitution (Fig. 8). Variations in the dose of donor DNA for S. mutans revealed high levels of transformation with saturating concentrations above $75 \mathrm{ng} \mathrm{mL}^{-1}$ for $\sim 4-\mathrm{kb}$ donors. A possible drawback to the method for single-base replacement may arise from activity of Hex repair systems. The mismatch repair system Hex modulates the yield of transformants for 1-base changes in S. pneumoniae, and a similar effect may be in operation in S. mutans (Claverys and Lacks, 1986). If so, it can be expected that certain 1-base substitutions may be disfavored by as much as two- to ten-fold, but that larger alterations would escape such repair. A second possible drawback arises from the possibility of errors during PCR amplification of the flanking DNA critical for precise targeting. However, modern generations of proof-reading polymerases are so accurate as to minimize this concern.

Since many isolates of $S$. mutans are known to produce and respond to XIP (Khan, 2015), and since the sequence of $c o m S$ is widely, perhaps universally, conserved within this species, the genome editing method described here may have wider application, beyond the reference strain UA159 that was used in these studies. Preparation of donor DNA is likely to present few technical hurdles. However, application of this method outside UA159 may face a variety of challenges rooted in the biology of the recipient competent cells. In certain media, for example, strain UA159 develops competence in only a subset of cells within a culture (Lemme et al., 2011; Reck et al., 2015; Son et al., 2015; Son et al., 2012). In strains that transform poorly, but have a minority of

fully competent cells, one can use two different pieces of donor DNA - one at an innocuous site with selection and a second DNA fragment carrying the desired mutation. Then the screening can be focused on selected transformants for the first marker, to identify the desired un-marked chromosomal mutation.

Finally, as similarly high direct editing rates were reported for competent cultures of $S$. pneumoniae, where 5-kb amplicons were used to make 1-bp substitutions (Tovpeko and Morrison, 
2014), it is likely that this direct editing strategy would be useful in other streptococcal species where competence development can be optimized. Such optimization will be facilitated by the recent recognition that all streptococci share the $\mathrm{SigX}$ regulator and either of two types of upstream pheromone signals -- CSP or XIP (Johnston et al., 2014). Experience over two decades has shown that these readily available peptide pheromones can short-circuit uncharacterized environmental factors to achieve very high rates of transformation.

\subsection{Conclusion}

Until the era of inexpensive whole-genome synthesis arrives, each strategy for targeted mutagenesis will represent a balance of choices among available tools and paths, choices made to minimize cost while maximizing precision, efficiency, and speed. The strategy described here for S. mutans can be applied directly to the widely studied reference strain UA159 and has the advantage of extreme simplicity, requiring construction of only one synthetic donor amplicon and a single transformation step, followed by a simple PCR screen among a few dozen clones to identify the desired mutant. The strategy depends on optimizing both partners in natural genetic transformation, donor DNA and competent recipient cells. The donor is provided as a specially designed pure gene amplicon, carrying the mutant sequence centrally located between flanking segments of homology of at least two kb, which ensure efficient and precise integration by the recombination machinery specific to competent cells. The recipients are highly competent cells, maintained in a persistent state of competence by treatment with the 7-residue synthetic competence XIP pheromone peptide in a chemically defined peptide-free medium.

\section{Acknowledgments.}

This work was supported in part by the National Science Foundation under grant no. MCB1020863, and by the Faculty of Dentistry, University of Oslo. We thank Kunal Desai for assistance with exploratory experiments. 


\section{References}

405

406

407

408

409

410

411

412

413

414

415

416

417

418

419

420

421

422

423

424

425

426

427

428

429

430

431

432

433

Banerjee A, Biswas I (2008). Markerless multiple-gene-deletion system for Streptococcus mutans. Applied and Environmental Microbiology 74(7):2037-2042.

Biswas I, Gruss A, Ehrlich SD, Maguin E (1993). High-efficiency gene inactivation and replacement system for gram-positive bacteria. Journal of Bacteriology 175(11):3628-3635.

Biswas I, Drake L, Johnson S, Thielen D (2007). Unmarked gene modification in Streptococcus mutans by a cotransformation strategy with a thermosensitive plasmid. Biotechniques 42(4):487-490.

Cato A, Jr., Guild WR (1968). Transformation and DNA size: I. Activity of fragments of defined size and a fit to a random double cross-over model. Journal of Molecular Biology 37(1):157-178.

Chang JC, LaSarre B, Jimenez JC, Aggarwal C, Federle MJ (2011). Two group A streptococcal peptide pheromones act through opposing Rgg regulators to control biofilm development. Plos Pathogens 7(8):e1002190.

Clarke JK (1924). On the bacterial factor in the etiology of dental caries. British Journal of Experimental Pathology 5(3):141-147.

Claverys JP, Lacks SA (1986). Heteroduplex deoxyribonucleic acid base mismatch repair in bacteria. Microbiological Reviews 50(2):133-165.

Cornejo OE, Lefebure T, Bitar PDP, Lang P, Richards VP, Eilertson K et al. (2013). Evolutionary and population genomics of the cavity causing bacteria Streptococcus mutans. Molecular Biology and Evolution 30(4):881-893.

Dalia AB, McDonough E, Camilli A (2014). Multiplex genome editing by natural transformation. Proceedings of the National Academy of Sciences of the United States of America 111(24):8937-8942.

Debowski AW, Gauntlett JC, Li H, Liao TT, Sehnal M, Nilsson HO et al. (2012). Xer-cise in Helicobacter pylori: One-step transformation for the construction of markerless gene deletions. Helicobacter 17(6):435443.

Desai K, Mashburn-Warren L, Federle MJ, Morrison DA (2012). Development of competence for genetic transformation of Streptococcus mutans in a chemically defined medium. Journal of Bacteriology 194(15):3774-3780. 
455

456

457

458

459

460

461

462

463

464

465

466

467

468

469

470

471

472

473

474

Farkas J, Stirrett K, Lipscomb GL, Nixon W, Scott RA, Adams MWW et al. (2012). Recombinogenic properties of Pyrococcus furiosus strain COM1 enable rapid selection of targeted mutants. Applied and Environmental Microbiology 78(13):4669-4676.

Fontaine L, Boutry C, de Frahan MH, Delplace B, Fremaux C, Horvath P et al. (2010a). A novel pheromone quorum-sensing system controls the development of natural competence in Streptococcus thermophilus and Streptococcus salivarius. Journal of Bacteriology 192(5):1444-1454.

Fontaine L, Dandoy D, Boutry C, Delplace B, de Frahan MH, Fremaux C et al. (2010b). Development of a versatile procedure based on natural transformation for marker-free targeted genetic modification in Streptococcus thermophilus. Applied and Environmental Microbiology 76(23):7870-7877.

Guo Q, Ahn SJ, Kaspar J, Zhou X, Burne RA (2014). Growth phase and pH influence peptide signaling for competence development in Streptococcus mutans. Journal of Bacteriology 196(2):227-236.

Gurney T, Fox MS (1968). Physical and genetic hybrids formed in bacterial transformation. Journal of Molecular Biology 32(1):83-100.

Havarstein LS, Coomaraswamy G, Morrison DA (1995). An unmodified heptadecapeptide pheromone induces competence for genetic transformation in Streptococcus pneumoniae. Proceedings of the National Academy of Sciences of the United States of America 92(24):11140-11144.

Johnston C, Campo N, Berge MJ, Polard P, Claverys JP (2014). Streptococcus pneumoniae, le transformiste. Trends in Microbiology 22(3):113-119.

Keller KL, Bender KS, Wall JD (2009). Development of a markerless genetic exchange system for Desulfovibrio vulgaris Hildenborough and its use in generating a strain with increased transformation efficiency. Applied and Environmental Microbiology 75(24):7682-7691.

Khan R, Rukke HV, Ricomini AP, Fimland G, Arntzen MO, Thiede B et al. (2012). Extracellular identification of a processed type II ComR/ComS pheromone of Streptococcus mutans. Journal of Bacteriology 194(15):3781-3788.

Khan R (2015). Genetic transformation in Streptococcus mutans: Role of CSP and XIP signaling pheromones. (Doctoral thesis). Oslo, Norway, University of Oslo.

Lacks S, Greenber.B, Carlson K (1967). Fate of donor DNA in pneumococcal transformation. Journal of Molecular Biology 29(3):327-347.

Lau PCY, Sung CK, Lee JH, Morrison DA, Cvitkovitch DG (2002). PCR ligation mutagenesis in transformable streptococci: application and efficiency. Journal of Microbiological Methods 49(2):193-205. 
496

502

503

504

505

506

507

508

509

510

511

512

513

514

515

Leibig M, Krismer B, Kolb M, Friede A, Gotz F, Bertram R (2008). Marker removal in staphylococci via Cre recombinase and different lox sites. Applied and Environmental Microbiology 74(5):1316-1323.

Lemme A, Grobe L, Reck M, Tomasch J, Wagner-Dobler I (2011). Subpopulation-Specific transcriptome analysis of competence stimulating peptide induced Streptococcus mutans. Journal of Bacteriology 193(8):1863-1877.

Li YH, Lau PCY, Lee JH, Ellen RP, Cvitkovitch DG (2001). Natural genetic transformation of Streptococcus mutans growing in biofilms. Journal of Bacteriology 183(3):897-908.

Lindler LE, Macrina FL (1986). Characterization of genetic transformation in Streptococcus mutans by using a novel high-efficiency plasmid marker rescue system. Journal of Bacteriology 166(2):658-665.

Lipscomb GL, Stirrett K, Schut GJ, Yang F, Jenney FE, Scott RA et al. (2011). Natural competence in the hyperthermophilic archaeon Pyrococcus furiosus facilitates genetic manipulation: Construction of markerless deletions of genes encoding the two cytoplasmic hydrogenases. Applied and Environmental Microbiology 77(7):2232-2238.

Loesche WJ (1986). Role of Streptococcus mutans in human dental decay. Microbiological Reviews 50(4):353-380.

Mashburn-Warren L, Morrison DA, Federle MJ (2010). A novel double-tryptophan peptide pheromone controls competence in Streptococcus spp. via an Rgg regulator. Molecular Microbiology 78(3):589-606.

Morrison DA, Guild WR (1972). Transformation and deoxyribonucleic acid size: extent of degradation on entry varies with size of donor. Journal of Bacteriology 112(3):1157-1168.

Morrison DA, Guild WR (1973). Breakage prior to entry of donor DNA in pneumococcus transformation. Biochimica Et Biophysica Acta 299(4):545-556.

Olson DG, Lynd LR (2012). Transformation of Clostridium thermocellum by electroporation. Methods in Enzymology 510(317-330.

Perry D, Kuramitsu HK (1981). Genetic transformation of Streptococcus mutans. Infection and Immunity 32(3):1295-1297.

Petersen FC, Fimland G, Scheie AA (2006). Purification and functional studies of a potent modified quorum-sensing peptide and a two-peptide bacteriocin in Streptococcus mutans. Molecular Microbiology 61(5):1322-1334. 
540

541

542

543

544

545

546

547

Reck M, Tomasch J, Wagner-Dobler I (2015). The Alternative Sigma Factor SigX Controls Bacteriocin Synthesis and Competence, the Two Quorum Sensing Regulated Traits in Streptococcus mutans. PLoS Genetics 11(7):e1005353.

Shah GR, Caufield PW (1993). Enhanced transformation of Streptococcus mutans by modifications in culture conditions. Analytical Biochemistry 214(1):343-346.

Son M, Ghoreishi D, Ahn SJ, Burne RA, Hagen SJ (2015). Sharply Tuned pH Response of Genetic Competence Regulation in Streptococcus mutans: a Microfluidic Study of the Environmental Sensitivity of comX. Applied and Environmental Microbiology 81(16):5622-5631.

Son MJ, Ahn SJ, Guo Q, Burne RA, Hagen SJ (2012). Microfluidic study of competence regulation in Streptococcus mutans: environmental inputs modulate bimodal and unimodal expression of comX. Molecular Microbiology 86(2):258-272.

Thiel A, Michoud G, Moalic Y, Flament D, Jebbar M (2014). Genetic manipulations of the hyperthermophilic piezophilic Archaeon Thermococcus barophilus. Applied and Environmental Microbiology 80(7):2299-2306.

Tovpeko Y, Morrison DA (2014). Competence for Genetic Transformation in Streptococcus pneumoniae: Mutations in $\sigma^{A}$ Bypass the comW Requirement. Journal of Bacteriology 196(21):3724-3734.

Vanderijn I, Kessler RE (1980). Growth characteristics of group A streptococci in a new chemically defined medium. Infection and Immunity 27(2):444-448.

Xie ZJ, Okinaga T, Qi FX, Zhang ZJ, Merritt J (2011). Cloning-Independent and Counterselectable markerless mutagenesis System in Streptococcus mutans. Applied and Environmental Microbiology 77(22):8025-8033.

Zhang CY, Whitaker RJ (2012). A broadly applicable gene knockout system for the thermoacidophilic archaeon Sulfolobus islandicus based on simvastatin selection. Microbiology 158(1513-1522. 
548 Table 1. Strains used.

\begin{tabular}{|c|c|c|}
\hline Name & Description & Source \\
\hline MW01 & UA159, but $\Delta$ comR $:$ CAT; $\mathrm{Cm}^{\mathrm{R}}$ & $\begin{array}{l}\text { (Mashburn-Warren et } \\
\text { al., 2010) }\end{array}$ \\
\hline MW04 & $\mathrm{UA} 159$, but $\Delta o p p D:: s p c ; \mathrm{Spc}^{\mathrm{R}}$ & $\begin{array}{l}\text { (Mashburn-Warren et } \\
\text { al., 2010) }\end{array}$ \\
\hline UA159 & Wild-type & ATCC 700610 \\
\hline SM045 & UA159, but $\Delta \operatorname{dex} A:: k a n ; \operatorname{Kan}^{\mathrm{R}}$ & UA159 x TPLP* \\
\hline SM059 & UA159, but $\mathrm{p}_{c i p} B^{-l u c}:: s p c ; \mathrm{Spc}^{\mathrm{R}}$ & (Khan et al., 2012) \\
\hline SM067 & $\mathrm{UA159,}$ but $\Delta o p p D:: s p c ; \mathrm{Spc}^{\mathrm{R}}$ & UA159 x MW04 \\
\hline SM068 & $\mathrm{UA} 159, p_{\text {sigX }}$-luc; $\mathrm{Spc}^{\mathrm{R}}$ & (Khan et al., 2012) \\
\hline SM089 & UA159, but $\Delta$ comS::ery; Erm $^{\mathrm{R}}$ & (Khan et al., 2012) \\
\hline SM091 & SM068, but $\Delta$ comS::ery; $\mathrm{Sp}^{\mathrm{R}} \operatorname{Erm}^{\mathrm{R}}$ & (Khan et al., 2012) \\
\hline SM156 & UA159, but $\Delta s m u \_60:: \operatorname{Kan} ; \operatorname{Kan}^{\mathrm{R}}$ & UA159 x TPLP* \\
\hline SM134 & SM089, but $\mathrm{P}_{\text {cipB }}-1 \mathrm{luc}:: s p c ; \mathrm{Erm}^{\mathrm{R}} \mathrm{Spc}^{\mathrm{R}}$ & SM089 x SM059 \\
\hline SM177 & SM068, but comE SigX-box inversion; $\mathrm{Spc}^{\mathrm{R}}$ & SM068 x aRJ04 \\
\hline SM179 & SM091, but comE SigX-box inversion; $\mathrm{Spc}^{\mathrm{R}} \mathrm{Erm}^{\mathrm{R}}$ & SM091 x aRJ04 \\
\hline SM188 & SM068, but c_105 1-bp substitution; Spc ${ }^{R}$ & SM068 x aRJ17 \\
\hline SM189 & SM091, but $\Delta \mathrm{DR}$ comE; $\mathrm{Spc}^{\mathrm{R}}$ & SM091 x aRJ18 \\
\hline SM190 & $\mathrm{SM} 134$, but $\Delta \mathrm{DR}$ comE; $\mathrm{Spc}^{\mathrm{R}}$ & SM134 x aRJ18 \\
\hline
\end{tabular}

*TPLP, three-piece ligation product; details available in Supplemental Table 1 
550

551 Table 2. Donor DNA amplicons

\begin{tabular}{|c|c|c|c|c|c|c|}
\hline ID & Marker & Source & $\begin{array}{c}\text { Total } \\
\text { Length, bp }\end{array}$ & Left arm & $\begin{array}{c}\text { Cassette or } \\
\text { Nucleotide } \\
\text { substitutions, } \\
\text { bp }\end{array}$ & Right arm, bp \\
\hline aRJ01 & $\triangle S M U .60:$ kan & SM156 & 8033 & 4075 & 1038 & 2920 \\
\hline aRJ02 & $\Delta d \operatorname{exA}:: k a n$ & SM045 & 6311 & 2574 & 884 & 2853 \\
\hline aRJ04 & p-comE SigX-box & $\begin{array}{l}\text { Assembly } \\
\text { or SM177 }\end{array}$ & 5757 & 2893 & Inv 8 bp & 2856 \\
\hline aRJ05 & p-comE SigX-box & SM177 & 8294 & 3987 & Inv8 bp & 4299 \\
\hline aRJ06 & p-comE SigX-box ${ }_{I N V}$ & SM177 & 6017 & 3030 & Inv 8 bp & 2979 \\
\hline aRJ07 & p-comE SigX-box ${ }_{I N V}$ & SM177 & 4037 & 1936 & Inv 8 bp & 2093 \\
\hline aRJ08 & p-comE SigX-box & SM177 & 2001 & 1054 & Inv 8 bp & 939 \\
\hline aRJ09 & p-comE SigX-box & SM177 & 1014 & 515 & Inv 8 bp & 491 \\
\hline aRJ12 & p-comE SigX-box ${ }_{I N V}$ & SM177 & 4158 & 3987 & Inv 6 bp & 163 \\
\hline aRJ13 & $\triangle S M U .60::$ kan & SM156 & 7077 & 3119 & 1038 & 2920 \\
\hline aRJ14 & $\triangle S M U .60::$ kan & SM156 & 5282 & 2142 & 1038 & 2102 \\
\hline aRJ15 & $\triangle S M U .60::$ kan & SM156 & 3076 & 1016 & 1038 & 1022 \\
\hline aRJ16 & $\triangle S M U .60::$ kan & SM156 & 2149 & 549 & 1038 & 562 \\
\hline aRJ17 & $\begin{array}{l}\text { c_105 1-bp } \\
\text { substitution }\end{array}$ & SM188 & 7575 & 3618 & 1 & 3956 \\
\hline aRJ18 & $\Delta D R$ comE & SM189 & 5116 & 2556 & 39 & 2560 \\
\hline
\end{tabular}

552

553 
Figure 1. Comparison of $\operatorname{sig} X$ expression profiles in CDM and TSB. Strain SM068 was grown in $100 \mu \mathrm{L}$ volumes of CDM or TSB in a 96 -well plate in ambient air at $37^{\circ} \mathrm{C}$ with $1 \mu \mathrm{M}$ XIP (Black) or $250 \mathrm{nM} \mathrm{CSP-18} \mathrm{(grey),} \mathrm{respectively.} \mathrm{(A)} \mathrm{Culture} \mathrm{density} \mathrm{and} \mathrm{(B)} \operatorname{sig} X$ expression (sig $X$ reporter luminescence measured as relative light units, RLU) were monitored periodically. The results are representative of two independent experiments.

Figure 2. Density-independent competence in CDM. Transformation of dilute CDM cultures

563

564

565

566

567

568

569

570

571

572

573

574

575

576

577

578

579

580

581

582

583

584

was measured following XIP treatment. A frozen stock of SM068 in CDM was used to inoculate $12 \mathrm{CDM}$ cultures at various initial optical densities. $\mathrm{OD}_{600}$ was measured for each culture after $4 \mathrm{~h}$, when SM089 genomic DNA $(1 \mathrm{ug} / \mathrm{ml})$ and XIP $(1 \mu \mathrm{M})$ were added. Transformants (grey) and total CFU (black) were determined after 2 hs further incubation.

Figure 3. Persistent competence in $\boldsymbol{S}$. mutans treated with XIP. Three cultures of UA159 growing in CDM were supplemented with XIP $(3 \mu \mathrm{M})$ at OD 0.07. (A) One culture was repeatedly assayed for competence by exposing 1-ml samples to $10 \mu \mathrm{g} / \mathrm{ml}$ of MW01 DNA for 5 min, treated with DNase I in TSB at $37 \mathrm{C}$ for $2 \mathrm{hrs}$ to stop further uptake and allow expression of the $\mathrm{Cm}^{\mathrm{R}}$ phenotype. (B) The other two cultures were supplemented with MW01 DNA at $10 \mu \mathrm{g} / \mathrm{ml}$ after 50 (grey) or $150 \mathrm{~min}$ (black) with XIP. Each was subsequently assayed for accumulation of $\mathrm{Cm}^{\mathrm{R}}$ transformants at 5- or 10- min intervals during $100 \mathrm{~min}$ at $37 \mathrm{C}$. Standard deviations for triplicate plate counts were $35 \%, 34 \%$, and $30 \%$ respectively.

Figure 4. Transformation as a function of amplicon DNA concentration. Strain SM068 was transformed with the $6.3-\mathrm{kb}$ amplicon donor aRJ02 in $200-\mu \mathrm{L}$ volumes of CDM with $1 \mu \mathrm{M}$ XIP for $3 \mathrm{~h}$. Amplicon concentrations varied from 0.3 to $150 \mathrm{ng} \mathrm{mL}-1$. The $\%$ of CFU containing a KanR transformant was determined by plating on TSB and TSB Kan agar. The results are averages from 3 to 4 replicates. Bars represent standard errors.

Figure 5. Segregation of pure transformant clones. Ex-transformation colonies growing on nonselective medium were analyzed for recipient and donor alleles by PCR. Plating on TSB was

Page 21 
606

607

608

609

610

611

612

613 614 638

done after incubation of SM068 with the 5.8-kb amplicon aRJ04 and XIP for $3-6$ hs. Each bar displays results for 12 colonies. Neg, only recipient allele observed (grey) ; Pure, only donor allele observed (maroon); Mixed, both alleles observed (pink). (B) Gel image of exemplary Pure, Neg, and Mixed colonies. M, Gene Ruler ${ }^{\mathrm{TM}} 1 \mathrm{~kb}$ DNA ladder. Control templates: INV, amplicon aRJ04, with SigX-box inversion; WT, UA159 gDNA. Screening primers were: FP919-FP920 (347-bp, for SigX-box inversion), and FP918-FP921 (194 bp, for WT).

Figure 6. Dependence of gene replacement efficiency on amplicon size. Transformation of SM068 in CDM with XIP by markerless SigX-box inversion fragments from strain SM177 (aRJ05-aRJ09), constructed with 0.5- to 4-kb arms, or by SMU.60-kan amplicons from strain SM156 (aRJ13 - aRJ16) with 0.5- to 3-kb arms at 150 or $300 \mathrm{ng} / \mathrm{mL}$. \% of Kan-selected transformants is indicated at left (SM156 amplicons), and unselected donor alleles at right (PCR screen; $\underline{\text { SM177 amplicons). }}$.

Figure 7. Effect of donor DNA length on segregation of pure recombinants. Strain SM068 was incubated with XIP and 0.1 nM DNA donor fragments carrying the SigX-box inversion for $3.5 \mathrm{~h}$ at $37^{\circ} \mathrm{C}$. Dilutions $\left(10^{-7}\right)$ were spread on TSB plates. For each donor, 24 colonies were screened by PCR to detect the donor allele, using primer pairs as in Fig. 5. Colony lysates giving a donor PCR band were re-analysed for recipient allele, to allow characterization as pure recipient, pure mutant (maroon) donor allele, or mixed (pink). Amplicon donors of defined size were prepared from strain SM177 as amplicons aRJ05-09 and aRJ12.

Figure 8. Summary of mutation designs. Target regions in each panel is at bottom, donor DNA amplicon at top, with desired alteration indicated in green. (A) SMU.60 deletion, (B) $\operatorname{dexA}$ deletion, (C) inversion of the putative SigX-box upstream of comE, (D) single base mutation in c105 (E) deletion of the ComE direct repeat (DR) binding site upstream of comE. Represented genes: kan, kanamycin resistance; SMU.60, alkylation repair protein; dexA, extracellular dextranase; comE, response regulator of the ComDE two-component signal transduction system; c105, putative ORF overlapping the 3-end of SMU.60. 
Figure 1

(A)

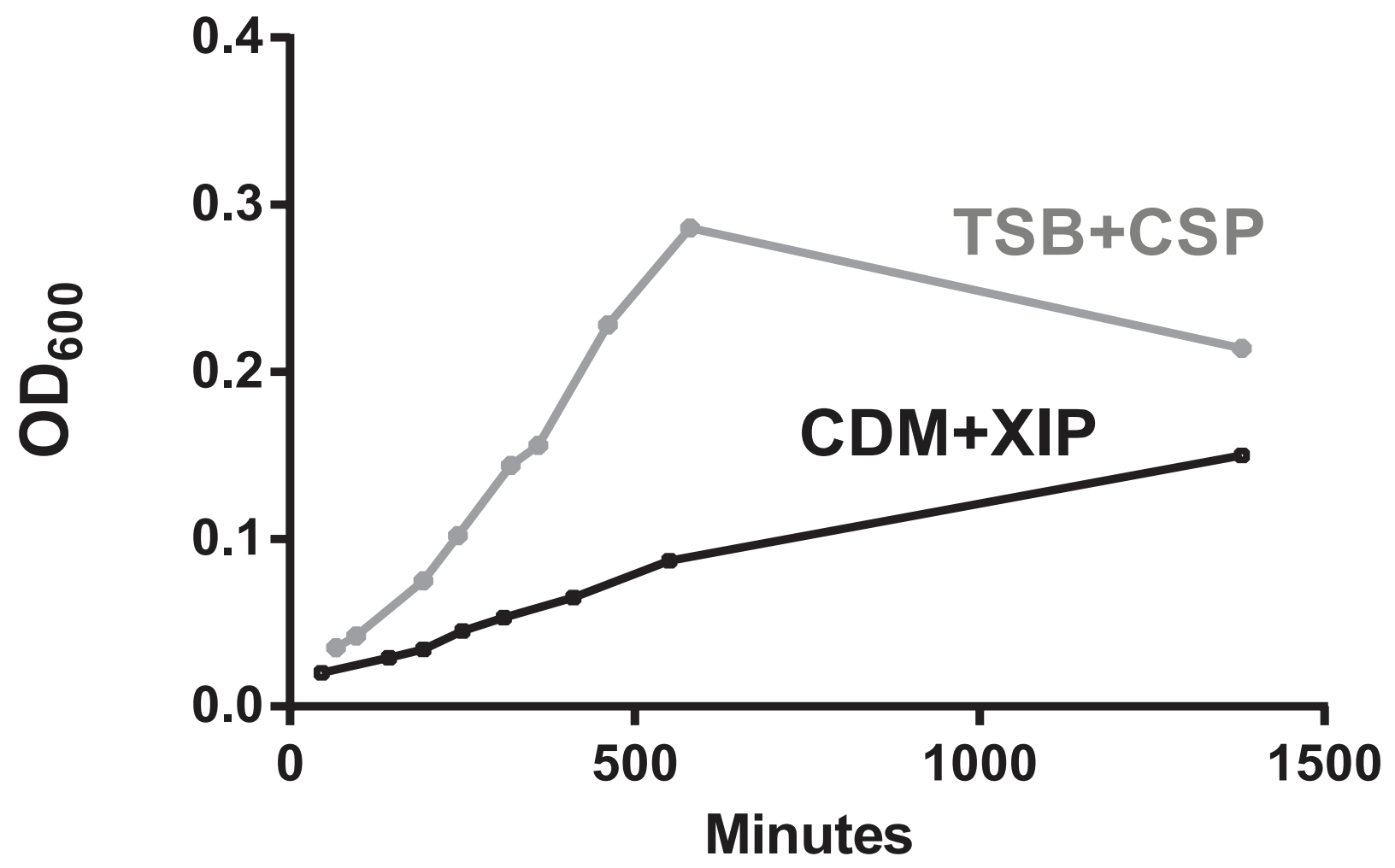


(B)

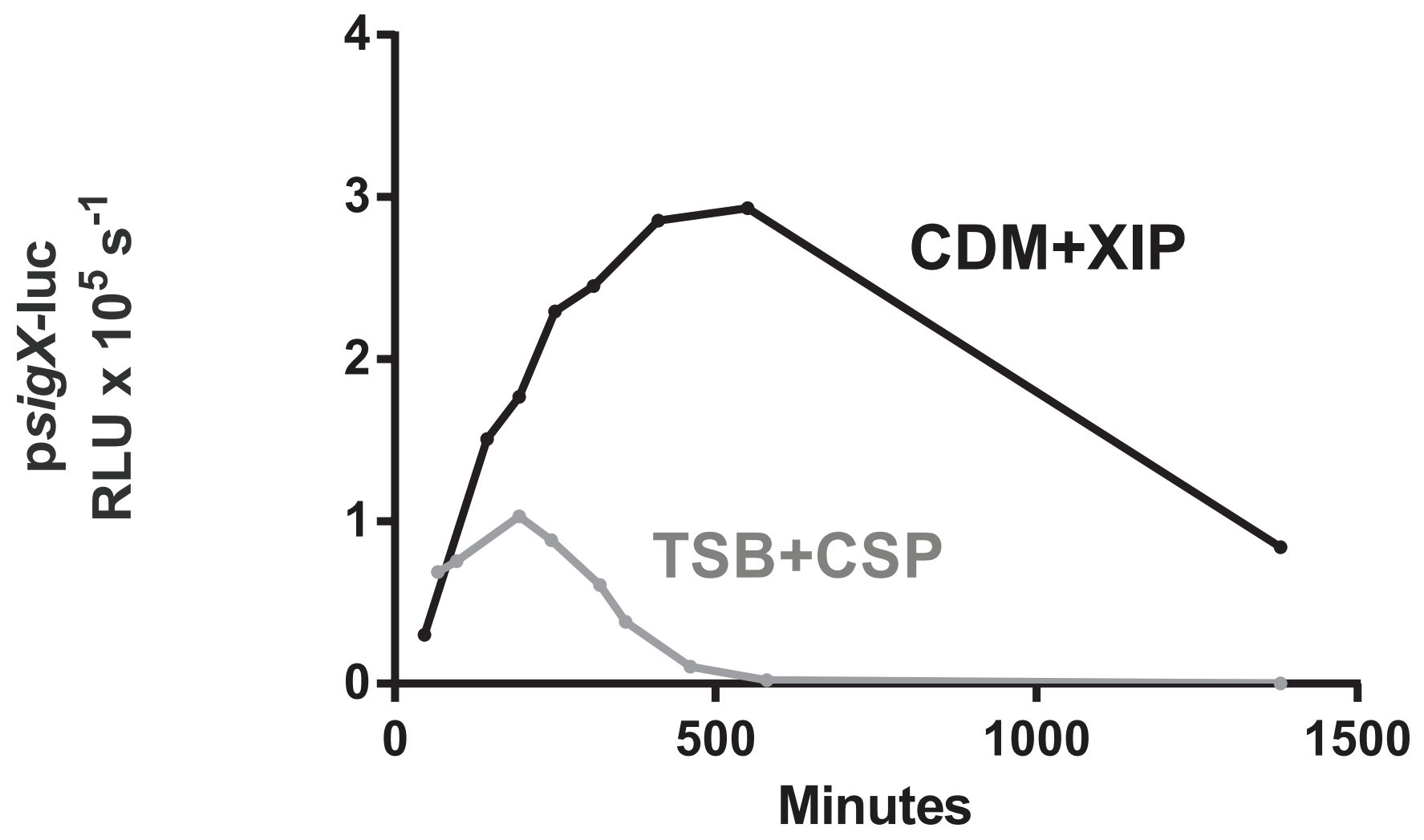


Figure 2

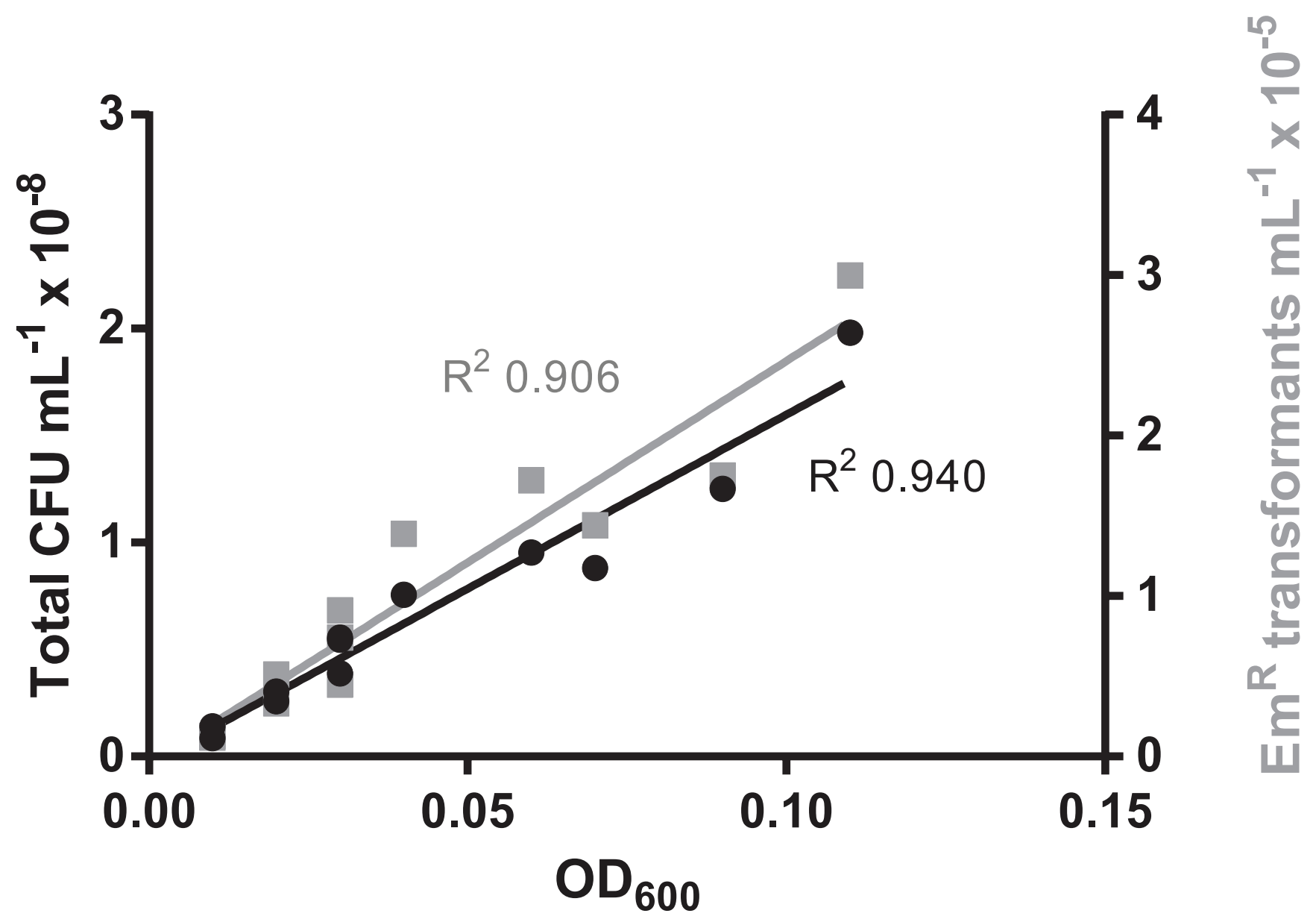


Figure 3

(A)

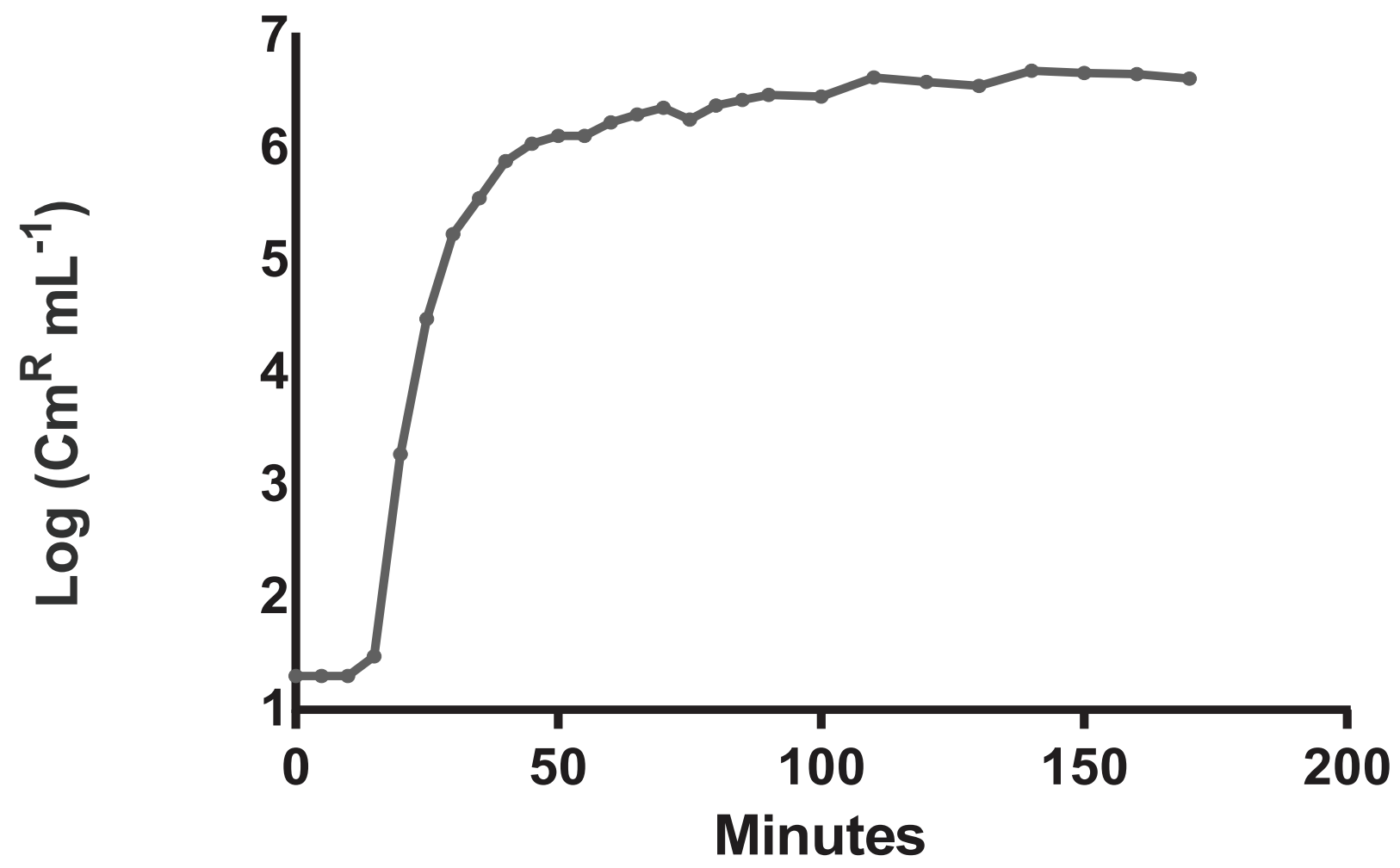


(B)

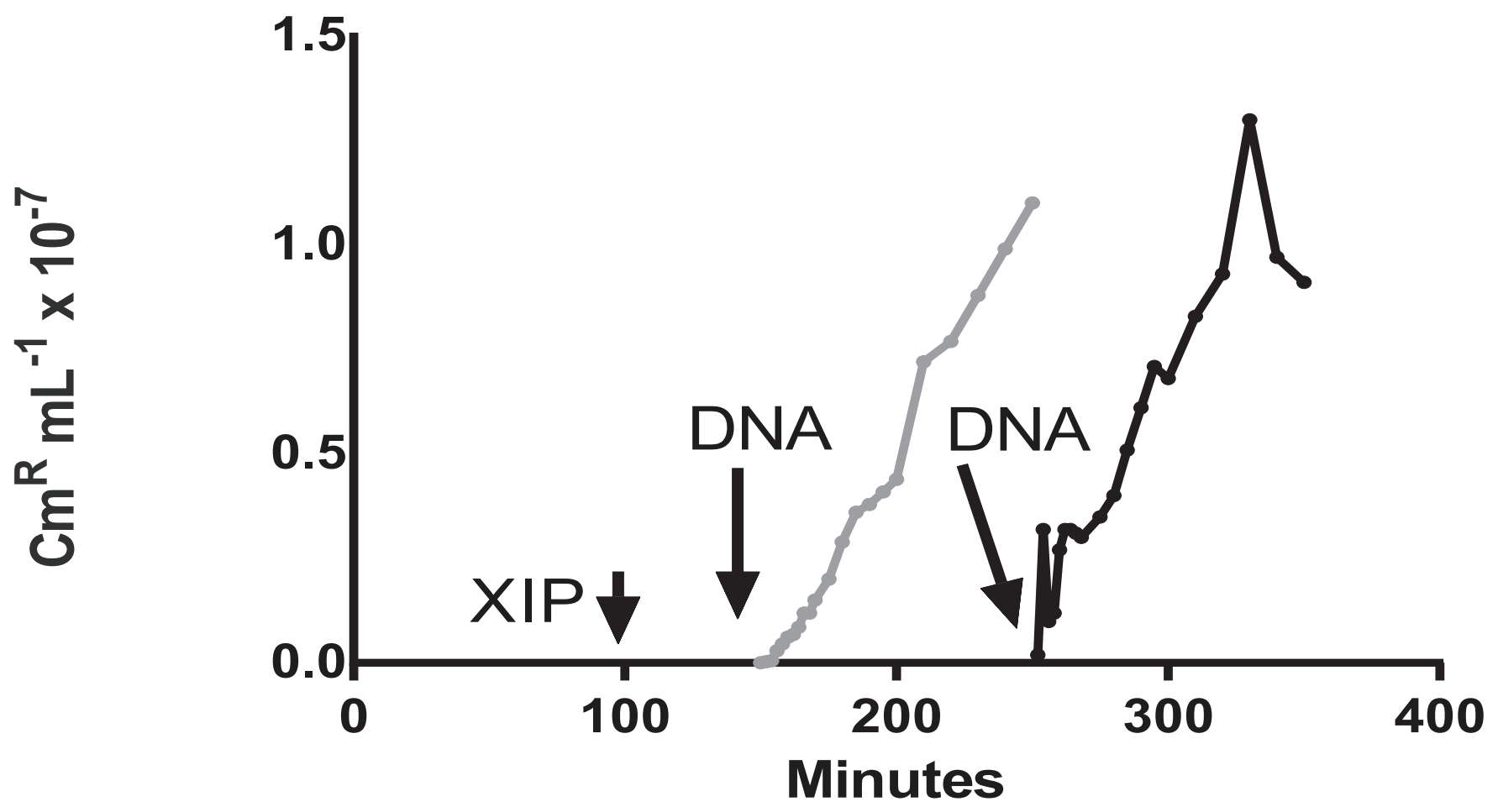


Figure 4

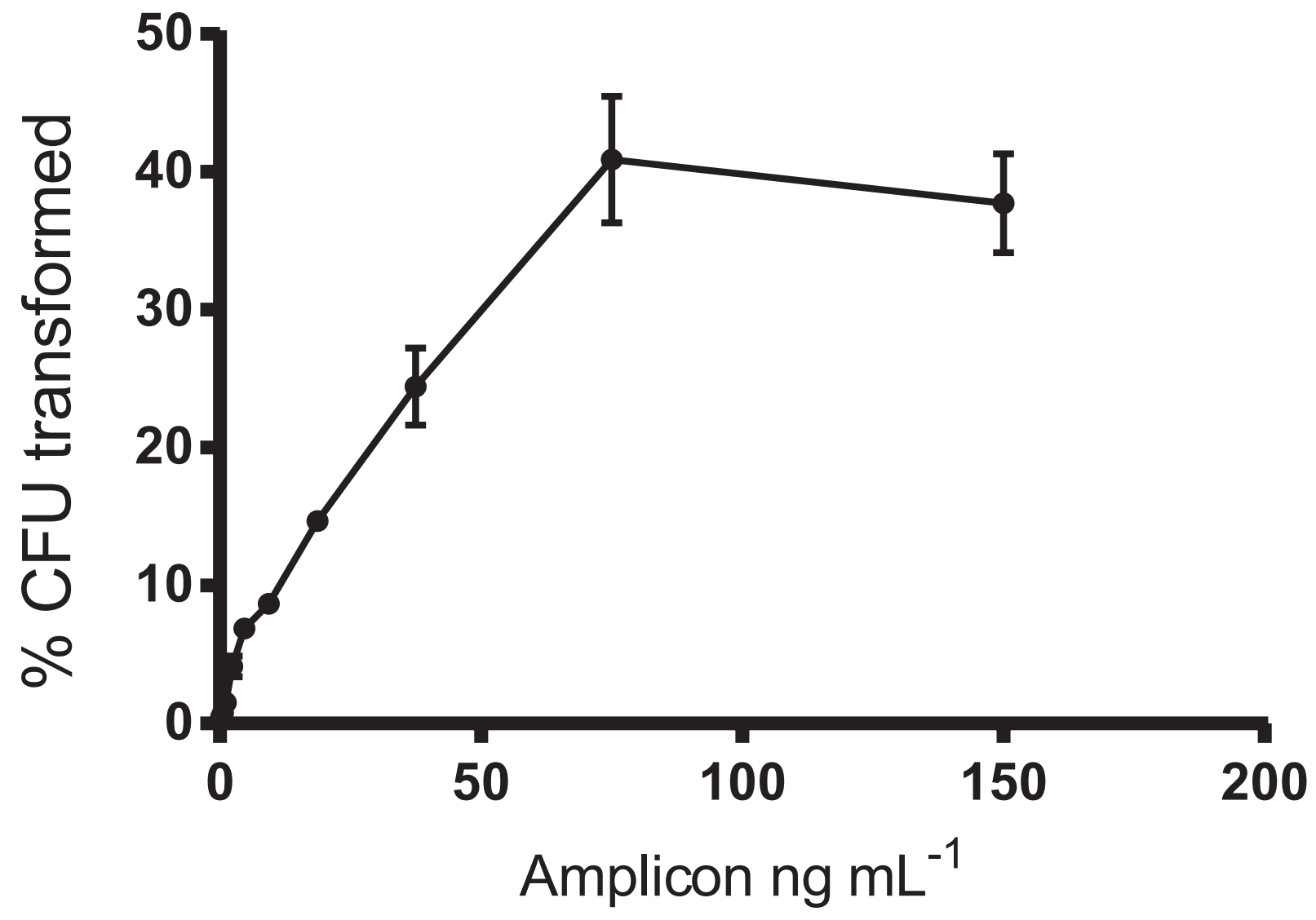


Figure 5

(A)

¿

c

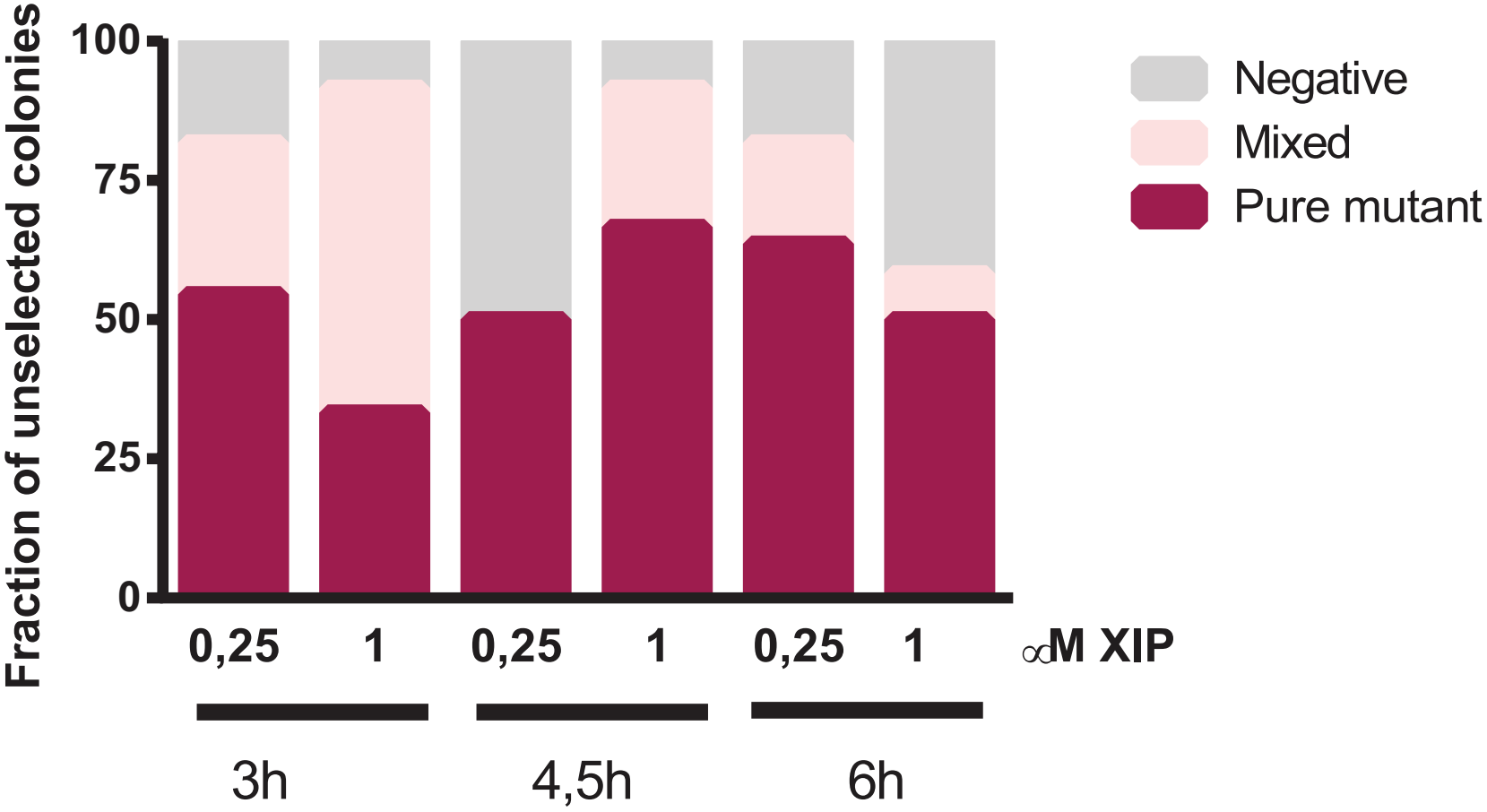


(B)

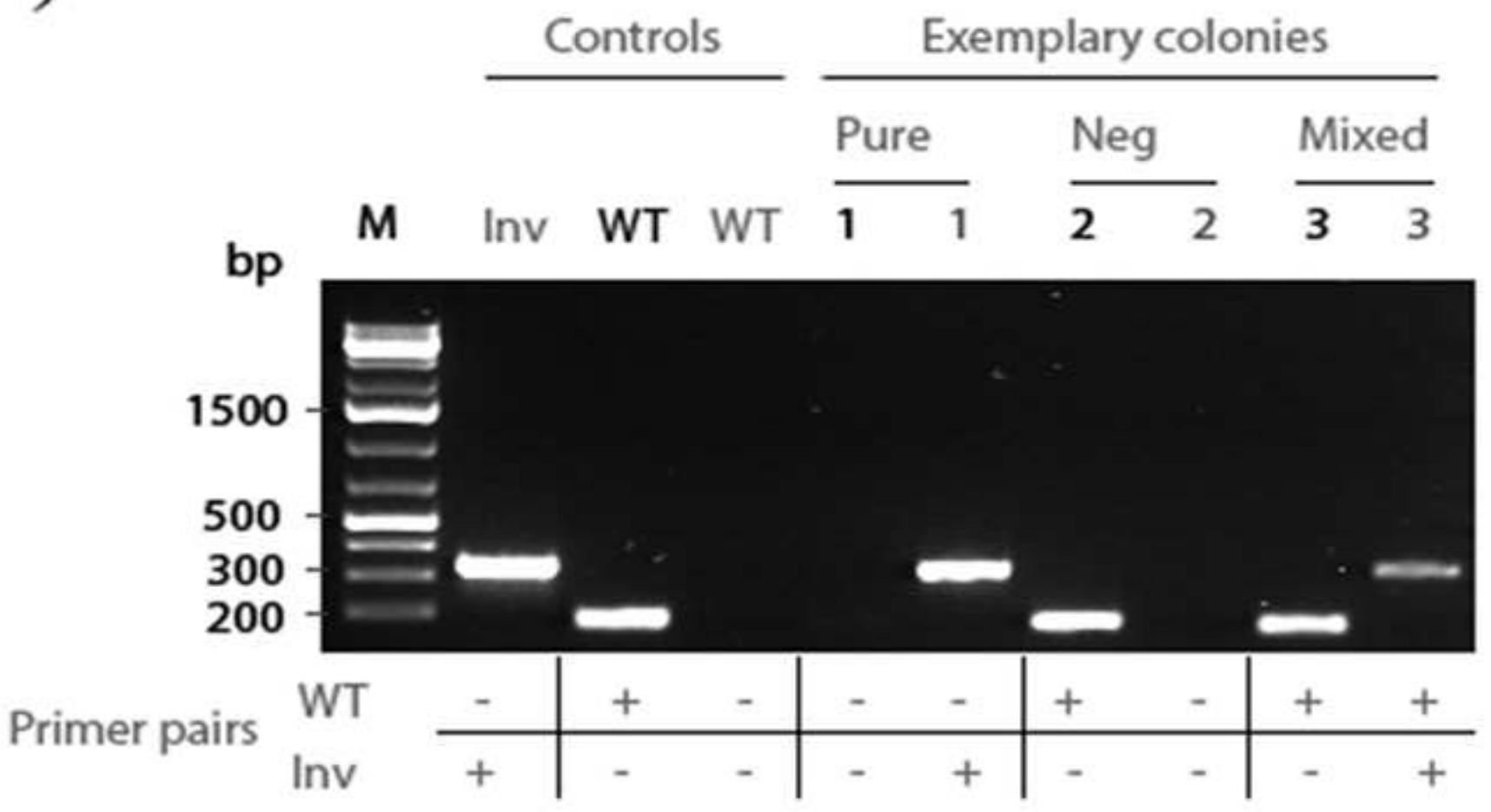


Figure 6

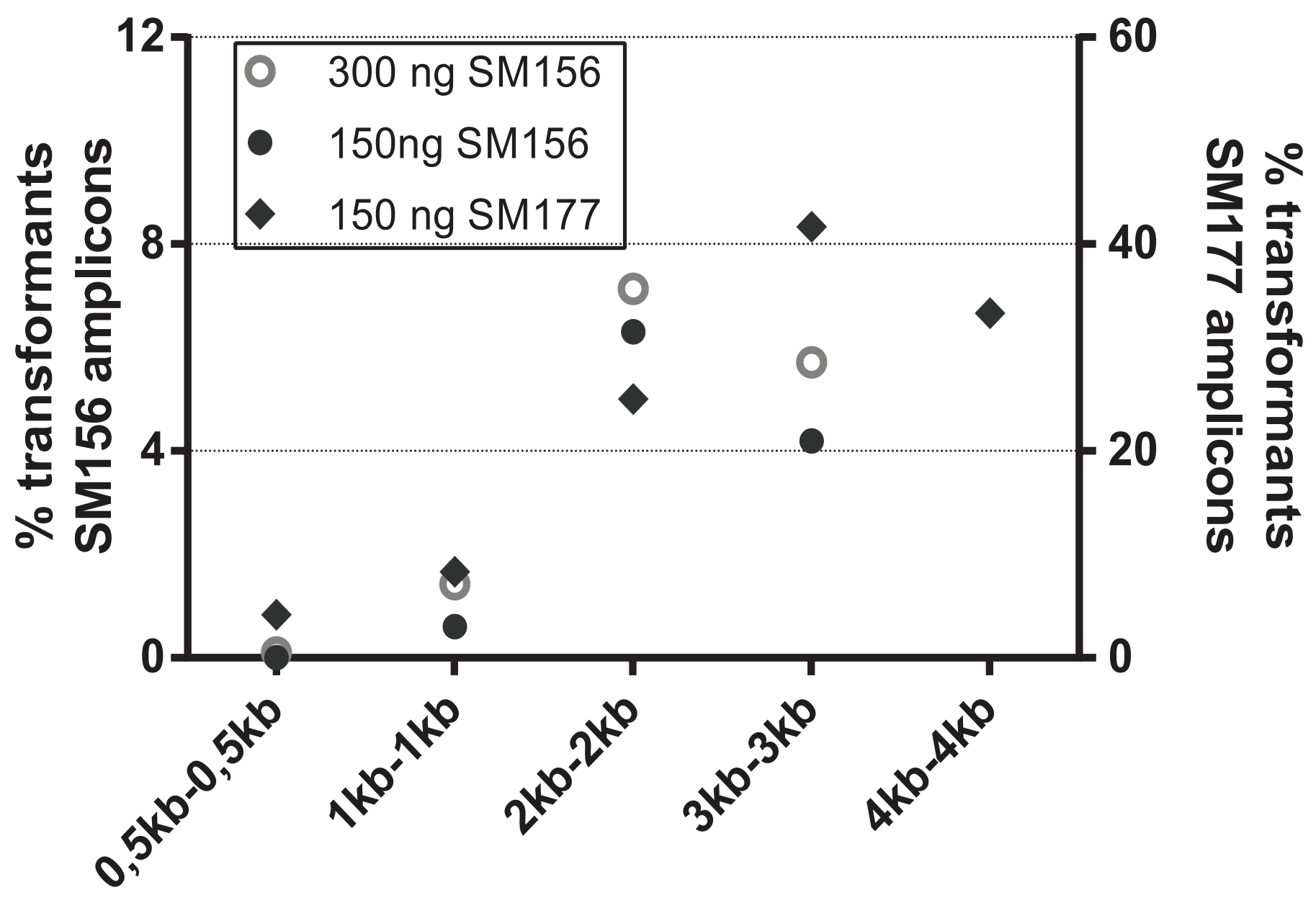


Figure 7

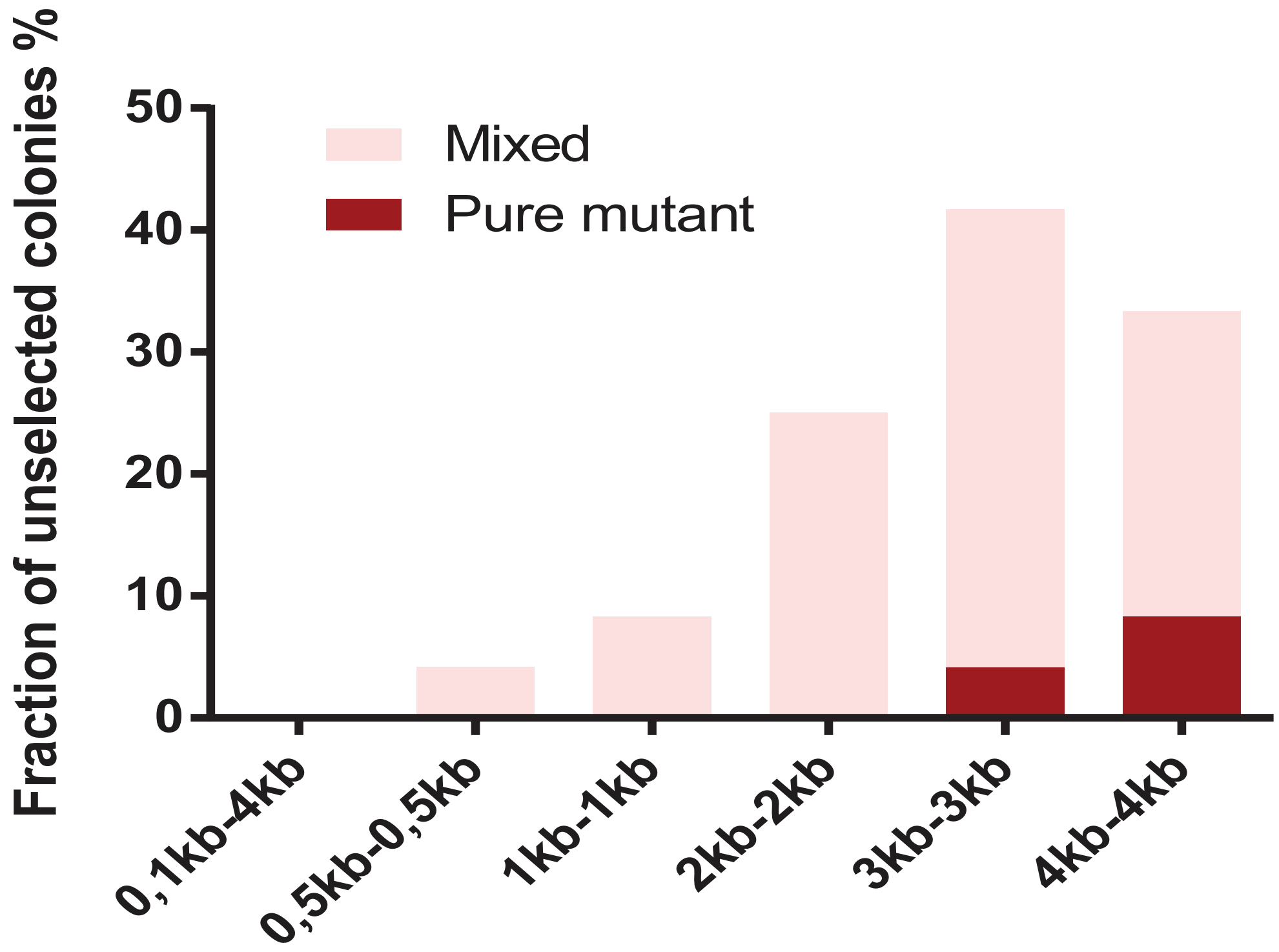


Figure 8

(A)

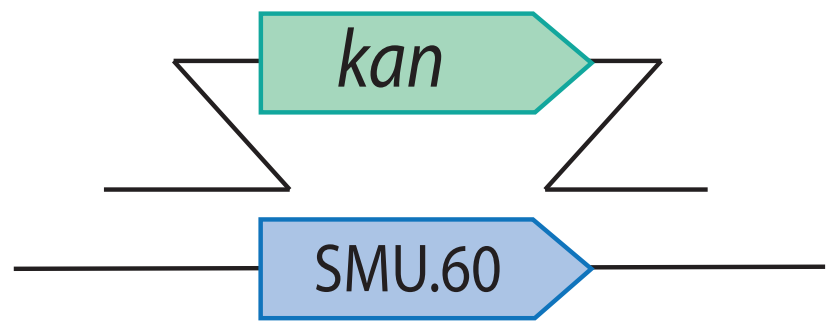

(B)

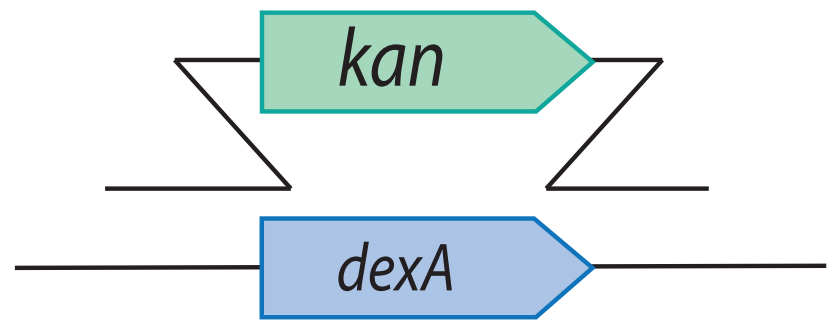

(C)

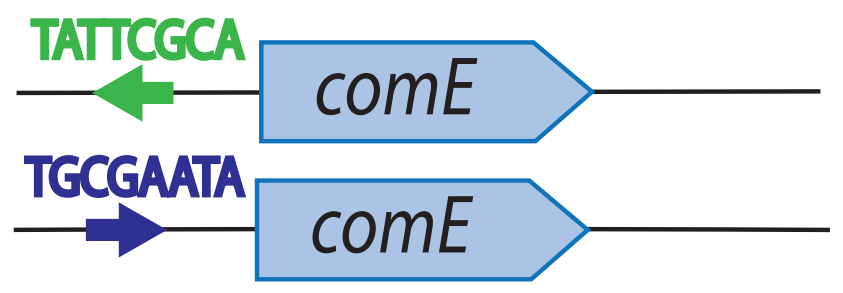

(D)

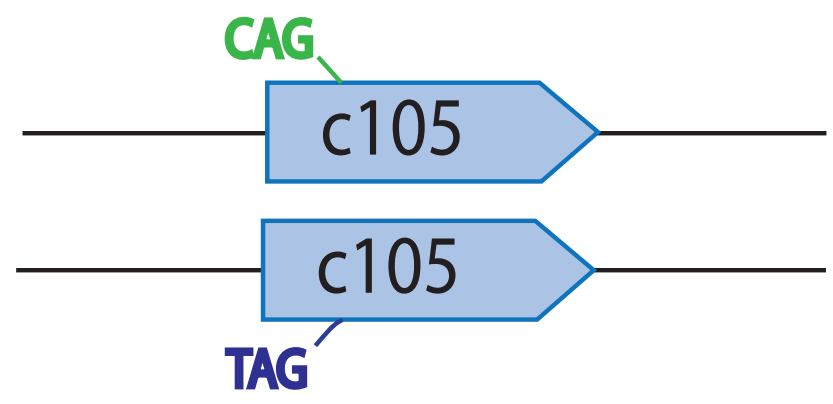

(E)

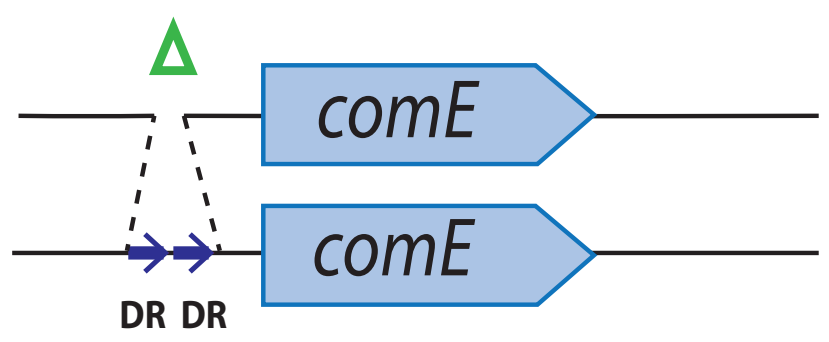


Graphical Abstract

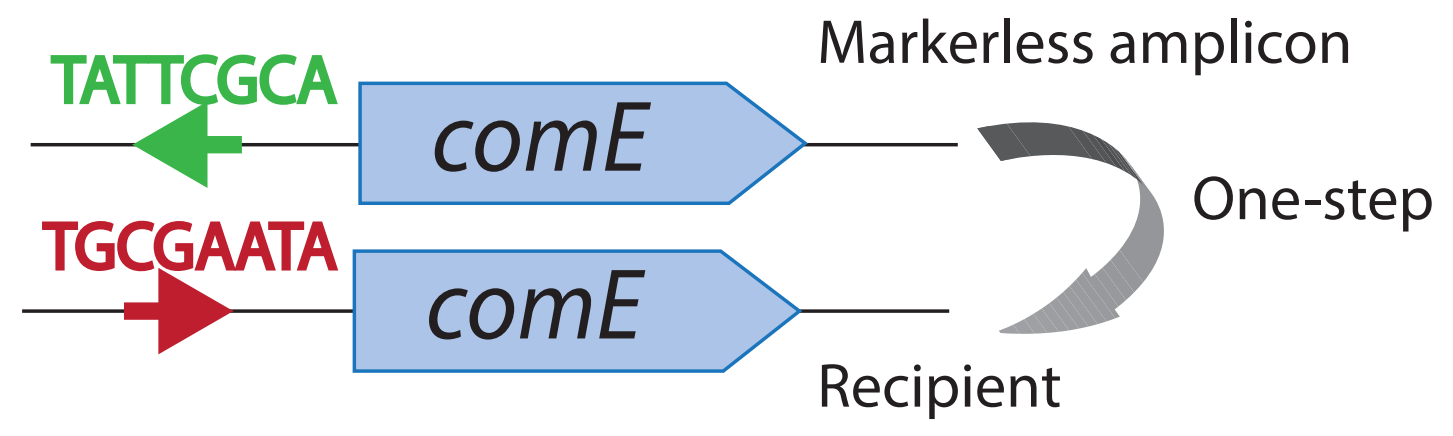

